\title{
Polyphenols content in potato tubers as influenced by insecticides different application
}

\author{
Zawartość polifenoli w bulwach ziemniaka \\ w warunkach stosowania różnych insektycydów
}

\author{
Krystyna Zarzecka, Marek Gugała, Honorata Dołęga, Anna Sikorska, Magdalena Zarzecka
}

\section{Summary}

The studies were conducted at the Agricultural Experimental Farm of the University of Natural Sciences and Humanites in Siedlce, in 2004-2006. The aim of the studies was to determine the influence selected insecticides (Actara $25 \mathrm{WG}-0.08 \mathrm{~kg} / \mathrm{ha}, \mathrm{Regent} 200 \mathrm{SC}$ $-0.1 \mathrm{l} / \mathrm{ha}$, Calypso $480 \mathrm{SC}$ - three doses: $0.05 ; 0.075 ; 0,1 \mathrm{l} / \mathrm{ha}$ ), used for the control of potato beetle, on the content of polyphenols in potato tubers of three potato cultivars (Wiking, Mors, Żagiel). The insecticides significantly increased the content of polyphenols as compared with the tubers harvested from the control variant without no chemical protection applied. The highest content of polyphenols was found in the tubers of the cultivar Mors, significantly less in Żagiel, and the least in Wiking.

Key words: potato, cultivars, potato beetle, insecticides, polyphenols

\section{Streszczenie}

Badania przeprowadzono w Rolniczej Stacji Doświadczalnej Uniwersytetu Przyrodniczo-Humanistycznego w Siedlcach, w latach 2004-2006. Celem ich było określenie wpływu wybranych insektycydów (Actara 25 WG w dawce 0,08 kg/ha, Regent 200 SC w dawce $0,1 \mathrm{l} / \mathrm{ha}$, Calypso 480 SC w trzech dawkach: 0,05; 0,075; 0,1 l/ha) stosowanych do zwalczania stonki ziemniaczanej na zawartość polifenoli w bulwach trzech odmian ziemniaka jadalnego: Wiking, Mors, Żagiel. Insektycydy wpłynęły na zwiększenie polifenoli w porównaniu do bulw z obiektu kontrolnego, na którym nie stosowano chemicznej ochrony. Najwięcej polifenoli zawierały bulwy odmiany Mors, istotnie mniej odmiany Żagiel, a najmniej odmiany Wiking.

Słowa kluczowe: ziemniak, odmiany, stonka ziemniaczana, insektycydy, polifenole

Uniwersytet Przyrodniczo-Humanistyczny w Siedlcach

Katedra Szczegółowej Uprawy Roślin

Prusa 14, 08-110 Siedlce

kzarzecka@uph.edu.pl 


\section{Wstęp / Introduction}

Żywność pochodzenia roślinnego stanowi bogate źródło związków o właściwościach przeciwutleniających. Związki te zwane antyoksydantami, reprezentowane sa przede wszystkim przez: polifenole, witaminy A, C i E, karotenoidy, kwasy organiczne, wapń, selen (Szajdek i Borowska 2004; Sikora i wsp. 2008). Spośród wymienionych przeciwutleniaczy to polifenole dominują w spożywanej żywności, a ich dzienne spożycie dochodzi do 1 grama. Związki te w ostatnich latach wzbudzają coraz większe zainteresowanie konsumentów i wytwórców produktów żywnościowych, gdyż wykazują wielokierunkowe działanie na żywność - $\mathrm{z}$ jednej strony kształtują smak i barwę, a z drugiej aktywność przeciwutleniająca, stabilizując tłuszcze i labilne składniki żywności (Budryn i Nebesny 2006; Jeszka i wsp. 2010; Gheribi 2011). Przypisuje się im istotną rolę w profilaktyce i zmniejszaniu ryzyka chorób cywilizacyjnych (Ziemlański i Wartanowicz 1999; Grajek 2004; Kuźnicki 2006).

Potencjalnym źródłem antyoksydantów w diecie Polaka są bulwy ziemniaka, warzywa z rodzaju Brassica, kawa, herbata, jabłka, napoje i piwo (Borowski i wsp. 2008; Sikora i wsp. 2008). Ziemniak w Polsce jest spożywany w znacznych ilościach, a na przestrzeni ostatnich dziesięciu lat jego konsumpcja wynosiła 112-131 kg na jedną osobę rocznie, stąd ważnym jest, aby technologia uprawy oddziaływała korzystnie na jakość bulw (Leszczyński 2000; Dzwonkowski i wsp. 2011).

Prowadzone badania miały na celu określenie wpływu wybranych insektycydów stosowanych do zwalczania stonki ziemniaczanej na zawartość polifenoli w bulwach ziemniaka jadalnego.

\section{Materiały i metody / Materials and methods}

Materiał do badań stanowiły bulwy ziemniaka jadalnego pochodzące $\mathrm{z}$ doświadczenia polowego, prowa- dzonego w latach 2004-2006 w Rolniczej Stacji Doświadczalnej Uniwersytetu Przyrodniczo-Humanistycznego w Siedlcach. Założono je metodą losowanych podbloków (split-plot), w trzech powtórzeniach, na glebie klasy IVa, kompleksu żytniego bardzo dobrego. Badanymi czynnikami były: I czynnik - trzy średnio wczesne odmiany ziemniaka: Mors, Wiking, Żagiel, II czynnik - sześć sposobów zwalczania stonki ziemniaczanej: 1. obiekt kontrolny - bez stosowania insektycydów, 2. Actara $25 \mathrm{WG}$ w dawce $0,08 \mathrm{~kg} / \mathrm{ha}, 3$. Regent $200 \mathrm{SC}$ w dawce 0,1 1/ha, 4. Calypso $480 \mathrm{SC}$ w dawce 0,05 1/ha, 5. Calypso $480 \mathrm{SC}$ w dawce 0,075 1/ha, 6 . Calypso $480 \mathrm{SC}$ w dawce $0,1 \mathrm{l} / \mathrm{ha}$.

Podczas prowadzenia badań (w latach 2004 i 2005) dawka preparatu Calypso $480 \mathrm{SC}$ nie była jeszcze ustalona, stąd insektycyd stosowano w ilościach: 0,$05 ; 0,075$ i 0,1 1/ha. Obecnie dawka zalecana tego środka wynosi $0,075 \mathrm{l} / \mathrm{ha}$. Insektycydy Actara 25 WG i Regent 200 SC aplikowano w ilościach zalecanych przez Instytut Ochrony Roślin. Insektycydy stosowano po wystapieniu szkodnika $\mathrm{w}$ stadium larwalnym $\mathrm{L}_{1} \mathrm{i}_{2}$.

Przedplonem ziemniaka była pszenica ozima. Jesienia każdego roku stosowano nawożenie naturalne obornikiem $\mathrm{w}$ ilości $25 \mathrm{t} / \mathrm{ha}$ oraz nawożenie mineralne fosforowopotasowe $\mathrm{W}$ ilości $\mathrm{P}-44,0 \mathrm{~kg} / \mathrm{ha}$ (superfosfat potrójny $46 \%$ ) i K - 124,5 kg/ha (sól potasowa $60 \%$ ). Nawozy azotowe wysiewano wiosną w ilości $100 \mathrm{~kg} \mathrm{~N} / \mathrm{ha}$ (saletra amonowa 34\%). Polifenole oznaczono w świeżej masie bulw ziemniaka metodą Swaina i Hillisa z wykorzystaniem odczynnika Folina-Ciocalteu (Swain i Hillis 1959). Otrzymane wyniki badań opracowano statystycznie za pomocą analizy wariancji, a ocenę istotności różnic przy poziomie istotności $\mathrm{p}=0,05$ pomiędzy porównywanymi średnimi za pomocą wielokrotnych przedziałów Tukeya.

W latach prowadzenia badań panowały zróżnicowane warunki pogodowe (tab. 1). W 2004 roku suma opadów była mniejsza o $22,8 \mathrm{~mm}$ w porównaniu ze średnią sumą opadów z okresu wieloletniego, a temperatura powietrza

Tabela 1. Warunki pogodowe podczas wegetacji ziemniaka

Table 1. Weather conditions during potato vegetation

\begin{tabular}{|c|c|c|c|c|c|c|c|}
\hline \multirow[b]{2}{*}{ Lata - Years } & \multicolumn{6}{|c|}{ Miesiące - Months } & \multirow{2}{*}{$\begin{array}{c}\text { Średnia } \\
\text { lub suma } \\
\text { kwiecień-wrzesień } \\
\text { Mean or sum } \\
\text { April-September }\end{array}$} \\
\hline & $\begin{array}{c}\text { kwiecień } \\
\text { April }\end{array}$ & $\begin{array}{l}\text { maj } \\
\text { May }\end{array}$ & $\begin{array}{l}\text { czerwiec } \\
\text { June }\end{array}$ & $\begin{array}{l}\text { lipiec } \\
\text { Jule }\end{array}$ & $\begin{array}{l}\text { sierpień } \\
\text { August }\end{array}$ & $\begin{array}{l}\text { wrzesień } \\
\text { September }\end{array}$ & \\
\hline \multicolumn{8}{|c|}{ Opady - Rainfall [mm] } \\
\hline $\begin{array}{l}2004 \\
2005 \\
2006 \\
\end{array}$ & $\begin{array}{l}35,9 \\
12,3 \\
29,8 \\
\end{array}$ & $\begin{array}{l}97,0 \\
64,7 \\
39,6 \\
\end{array}$ & $\begin{array}{l}52,8 \\
44,1 \\
24,0 \\
\end{array}$ & $\begin{array}{l}49,0 \\
86,5 \\
16,2 \\
\end{array}$ & $\begin{array}{c}66,8 \\
45,4 \\
228,1 \\
\end{array}$ & $\begin{array}{l}19,5 \\
15,8 \\
20,9 \\
\end{array}$ & $\begin{array}{l}320,9 \\
268,8 \\
358,6 \\
\end{array}$ \\
\hline $\begin{array}{l}\text { Średnia dla lat } 1981-1995 \\
\text { Mean values for } 1981-1995\end{array}$ & 52,3 & 50,0 & 68,2 & 45,7 & 66,8 & 60,7 & 343,7 \\
\hline \multicolumn{8}{|c|}{ Temperatura powietrza - Air temperature $\left[{ }^{\circ} \mathrm{C}\right]$} \\
\hline $\begin{array}{l}2004 \\
2005 \\
2006\end{array}$ & $\begin{array}{l}8,0 \\
8,7 \\
8,4\end{array}$ & $\begin{array}{l}11,7 \\
13,0 \\
13,6\end{array}$ & $\begin{array}{l}15,5 \\
15,9 \\
17,2\end{array}$ & $\begin{array}{l}17,5 \\
20,2 \\
22,3\end{array}$ & $\begin{array}{l}18,9 \\
17,5 \\
18,0\end{array}$ & $\begin{array}{l}13,0 \\
15,0 \\
15,4\end{array}$ & $\begin{array}{l}14,1 \\
15,0 \\
15,8\end{array}$ \\
\hline $\begin{array}{l}\text { Średnia dla lat } 1981-1995 \\
\text { Mean values for } 1981-1995\end{array}$ & 7,7 & 10,0 & 16,1 & 19,3 & 18,0 & 13,0 & 14,0 \\
\hline
\end{tabular}


zbliżona do średniej wieloletniej. W 2005 roku opady były mniejsze od średniej wieloletniej o $74,9 \mathrm{~mm}$. W miesiącach kwietniu, czerwcu, sierpniu i wrześniu warunki wilgotnościowe były niekorzystne, a temperatury powietrza zróżnicowane. W roku 2006 zanotowano największe opady, ale wystąpiły duże wahania w miesiącach letnich. W czerwcu opady były mniejsze o 44,2 mm, w lipcu o 29,5 mm, natomiast w sierpniu większe o $161,3 \mathrm{~mm}$ w odniesieniu do średniej sumy wieloletniej. Średnia temperatura powietrza $\mathrm{w}$ tym sezonie wegetacyjnym była większa o $1,8^{\circ} \mathrm{C}$ od średniej z okresu wieloletniego.

\section{Wyniki i dyskusja / Results and discussion}

Zawartość polifenoli w bulwach ziemniaka jadalnego kształtowała się od 181,7 do $258,9 \mathrm{mg} / \mathrm{kg}$ świeżej masy i była zbliżona do ilości podawanej przez innych autorów (Hamouz i wsp. 2006; Borowski i wsp. 2008; Zarzecka i Gugała 2011) (tab. 2, 3, 4). Zależała ona istotnie od insektycydów zastosowanych do zwalczania stonki ziemniaczanej, uprawianych odmian i warunków pogodowych w latach prowadzenia badań.

Tabela 2. Zawartość polifenoli w bulwach ziemniaka [mg/kg świeżej masy]

Table 2. Content of polyphenols in potato tubers $[\mathrm{mg} / \mathrm{kg}$ fresh matter]

\begin{tabular}{|c|c|c|c|c|}
\hline \multirow{2}{*}{$\begin{array}{l}\text { Sposoby zwalczania stonki ziemniaczanej } \\
\text { Potato beetle control methods }\end{array}$} & \multicolumn{3}{|c|}{ Odmiany - Cultivars } & \multirow{2}{*}{$\begin{array}{l}\text { Średnio } \\
\text { Mean }\end{array}$} \\
\hline & Wiking & Mors & Żagiel & \\
\hline $\begin{array}{l}\text { 1. Obiekt kontrolny - Control object } \\
\text { 2. Actara } 25 \mathrm{WG}-0,08 \mathrm{~kg} / \mathrm{ha} \\
\text { 3. Regent } 200 \mathrm{SC}-0,11 / \mathrm{ha} \\
\text { 4. Calypso } 480 \mathrm{SC}-0,05 \mathrm{l} / \mathrm{ha} \\
\text { 5. Calypso } 480 \mathrm{SC}-0,075 \mathrm{l} / \mathrm{ha} \\
\text { 6. Calypso } 480 \mathrm{SC}-0,1 \mathrm{l} / \mathrm{ha}\end{array}$ & $\begin{array}{l}181,7 \\
187,3 \\
184,7 \\
182,0 \\
182,0 \\
183,6\end{array}$ & $\begin{array}{l}239,0 \\
241,2 \\
245,7 \\
238,8 \\
244,6 \\
245,7\end{array}$ & $\begin{array}{l}216,9 \\
224,6 \\
220,8 \\
218,9 \\
222,4 \\
221,9\end{array}$ & $\begin{array}{l}212,5 \\
217,7 \\
217,1 \\
213,2 \\
216,3 \\
217,1\end{array}$ \\
\hline Średnio - Mean & 183,5 & 242,5 & 220,9 & \\
\hline \multicolumn{4}{|c|}{$\begin{array}{l}\text { NIR }(0,05) \text { - LSD }(0.05) \\
\text { Odmiany - Cultivars } \\
\text { Insektycydy do zwalczania stonki ziemniaczanej - Insecticides for potato beetle control } \\
\text { Odmiany x insektycydy do zwalczania stonki ziemniaczanej - Cultivars x insecticides for potato beetle control }\end{array}$} & $\begin{array}{l}4,1 \\
2,8 \\
\text { r.n. }\end{array}$ \\
\hline
\end{tabular}

r.n. - różnice nieistotne - not significant differences

Tabela 3. Zawartość polifenoli w zależności od sposobów zwalczania stonki ziemniaczanej i warunków pogodowych [mg/kg świeżej masy]

Table 3. Content of polyphenols depending on methods for potato beetle control and weather conditions [mg/kg fresh matter]

\begin{tabular}{|c|c|c|c|}
\hline \multirow{2}{*}{$\begin{array}{l}\text { Sposoby zwalczania stonki ziemniaczanej } \\
\text { Potato beetle control methods }\end{array}$} & \multicolumn{3}{|c|}{ Lata - Years } \\
\hline & 2004 & 2005 & 2006 \\
\hline $\begin{array}{l}\text { 1. Obiekt kontrolny - Control object } \\
\text { 2. Actara } 25 \mathrm{WG}-0,08 \mathrm{~kg} / \mathrm{ha} \\
\text { 3. Regent } 200 \mathrm{SC}-0,1 \mathrm{l} / \mathrm{ha} \\
\text { 4. Calypso } 480 \mathrm{SC}-0,05 \mathrm{l} / \mathrm{ha} \\
\text { 5. Calypso } 480 \mathrm{SC}-0,075 \mathrm{l} / \mathrm{ha} \\
\text { 6. Calypso } 480 \mathrm{SC}-0,11 / \mathrm{ha}\end{array}$ & $\begin{array}{l}207,9 \\
213,6 \\
212,9 \\
208,3 \\
212,5 \\
213,4 \\
\end{array}$ & $\begin{array}{l}210,6 \\
215,7 \\
217,3 \\
211,5 \\
215,9 \\
216,9\end{array}$ & $\begin{array}{l}219,0 \\
223,8 \\
221,0 \\
219,6 \\
220,5 \\
220,9\end{array}$ \\
\hline Średnio - Mean & 211,4 & 214,7 & 220,8 \\
\hline \multicolumn{3}{|c|}{$\begin{array}{l}\text { NIR }(0,05) \text { - LSD }(0.05) \\
\text { Lata - Years } \\
\text { Insektycydy do zwalczania stonki ziemniaczanej - Insecticides for potato beetle control } \\
\text { Lata x insektycydy do zwalczania stonki ziemniaczanej - Years x insecticides for potato betele control }\end{array}$} & $\begin{array}{l}4,1 \\
2,8 \\
\text { r.n. }\end{array}$ \\
\hline
\end{tabular}

r.n. - różnice nieistotne - not significant differences

Insektycydy (Actara $25 \mathrm{WG}$, Regent $200 \mathrm{SC}$, Calypso 480 SC) zastosowane do zwalczania stonki ziemniaczanej zwiększały istotnie zawartość polifenoli w bulwach ziemniaka w porównaniu do obiektu kontrolnego bez ochrony chemicznej (tab. 2). Najwięcej związków fenolowych stwierdzono $\mathrm{w}$ bulwach zebranych $\mathrm{z}$ poletek opryskiwanych preparatami Actara 25 WG, Regent 200 SC oraz Calypso 480 SC (stosowanymi w najwyższej dawce). Tendencję tę obserwowano u odmiany Wiking, natomiast u odmiany Mors wpływ preparatu Actara 25 WG nie był istotny w porównaniu do obiektu kontrolnego, a u odmiany Żagiel najwięcej polifenoli kumulowały bulwy zebrane z obiektów 1., 5. i 6. Mimo zróżnicowanej reakcji odmian interakcja odmian ze sposobami zwalczania stonki nie została potwierdzona statystycznie. Również w badaniach Antoniusa i wsp. (2001) oraz Kraski (2002) stwierdzono zwiększoną zawartość polifenoli pod wpływem chemicznej ochrony ziemniaka w porównaniu do bulw pochodzących z obiektu kontrolnego. Wzrost polifenoli obserwowali Zarzecka i Gugała (2011) - pod wpływem herbicydów, 
Tabela 4. Zawartość polifenoli w zależności od odmian i warunków pogodowych [mg/kg świeżej masy]

Table 4. Content of polyphenols depending on cultivars and weather conditions [mg/kg fresh matter]

\begin{tabular}{l|c|c|c|c}
\hline \multirow{2}{*}{ Lata - Years } & \multicolumn{2}{|c|}{ Odmiany - Cultivars } & \multirow{2}{*}{$\begin{array}{c}\text { Średnio } \\
\text { Mean }\end{array}$} \\
\cline { 2 - 5 } & Wiking & Mors & Żagiel & 211,4 \\
\multicolumn{1}{c|}{2004} & 182,7 & 232,1 & 219,6 & 214,7 \\
2005 & 184,0 & 236,6 & 223,4 & 220,8 \\
\hline Średnio - Mean & 183,8 & 258,9 & 219,8 & 215,7 \\
\hline NIR (0,05) - LSD (0.05) & 183,5 & 242,5 & 220,9 & \\
Lata - Years & & & 4,1 \\
Odmiany - Cultivars & & & \\
Lata x odmiany - Years x cultivars & & & \\
\hline
\end{tabular}

Rudzińska i Mikos-Bielak (1998) - po zastosowaniu regulatorów wzrostu. Marwaha (1988) wykazał, że syntetyczne nematocydy zmniejszały zawartość związków fenolowych w bulwach ziemniaka.

$\mathrm{Z}$ porównywanych odmian największą zawartością polifenoli w bulwach odznaczała się odmiana Mors średnio 242,5 mg/kg, istotnie mniejszą odmiana Żagiel, a najmniejszą odmiana Wiking. O wpływie odmian na tę cechę donoszą także Rudzińska i Mikos-Bielak (1998) oraz Hamouz i wsp. (2006, 2010).

Również lata, w których prowadzono badania istotnie różnicowały omawianą cechę (tab. 3, 4). Najmniej polifenoli gromadziły bulwy w 2004 roku, który był najchłodniejszy, natomiast istotnie więcej w sezonie 2006 roku, który był najcieplejszy i najbardziej wilgotny.

We wszystkich latach badań wystąiła tendencja do wzrostu zawartości polifenoli pod wpływem insektycydów, przy czym współdziałanie tych czynników nie zostało potwierdzone statystycznie. Zaobserwowano natomiast różną reakcję odmian na warunki wilgotnościowotermiczne w latach badań. Najmniej polifenoli gromadziły trzy badane odmiany w chłodnym 2004 roku, a najwięcej odmiana Mors w 2006 roku, zaś odmiany Wiking i Żagiel w 2005 roku. Tę zróżnicowaną reakcję jadalnych odmian ziemniaka potwierdza udowodniona statystycznie interakcja cech genetycznych odmian z latami badań. Oddzia- ływanie warunków klimatycznych na omawianą cechę obserwowali także Antonius i wsp. (2001), Kraska (2002), Hamouz i wsp. (2006, 2010) oraz Zarzecka i Gugała (2011). Zdaniem Kołodziejczyka i wsp. (2010) insektycydy chemiczne zwalczające stonkę ziemniaczaną chroniły rośliny ziemniaka przed redukcją powierzchni asymilacyjnej, co mogło wpływać na skład chemiczny bulw.

\section{Wnioski / Conclusions}

1. Trzyletnie badania wykazały, że zawartość polifenoli w bulwach ziemniaka zależała od insektycydów stosowanych przeciw stonce ziemniaczanej, odmian i warunków pogodowych w latach badań.

2. Wszystkie insektycydy, z wyjątkiem środka Calypso 480 SC stosowanego w najmniejszej dawce 0,05 1/ha, zwiększały zawartość polifenoli w porównaniu do bulw zebranych $\mathrm{z}$ obiektu kontrolnego niechronionego chemicznie.

3. Odmiany uprawiane $\mathrm{w}$ doświadczeniu różniły się istotnie pod względem zawartości polifenoli. Najwięcej tych związków gromadziła odmiana Mors, istotnie mniej odmiana Żagiel, a najmniej odmiana Wiking.

\section{Literatura / References}

Antonius G.F., Lee Ch.M., Snyder J.C. 2001. Sustainable soil management practices and quality of potato grown on erodible lands. J. Environ. Sci. Health, B 36 (4): 435-444.

Borowski J., Szajdek A., Borowska E.J. 2008. Charakterystyka chemiczna i aktywność biologiczna warzyw z terenu Olsztyna. Bromat. Chem. Toksykol. 3: 333-337.

Budryn G., Nebesny E. 2006. Fenolokwasy - ich właściwości, występowanie w surowcach roślinnych, wchłanianie i przemiany metaboliczne. Bromat. Chem. Toksykol. 2: 103-110.

Dzwonkowski W., Szczepaniak I., Zdziarska T., Mieczkowski M. 2011. Popyt na ziemniaki: s. 12-19. W: „Rynek Ziemniaka. Stan i Perspektywy". Analizy rynkowe. IERiGŻ - PIB, ARR, MRiRW 3: 12-19.

Gheribi E. 2011. Związki polifenolowe w owocach i warzywach. Medycyna Rodzinna 4: 11-15.

Grajek W. 2004. Rola przeciwutleniaczy w zmniejszaniu ryzyka wystapienia nowotworów i chorób układu krążenia. Żywność Nauka Technologia Jakość 1 (38): 3-11.

Hamouz K., Lachman J., Dvořák P., Čepl J., Šařec P. 2006. Influence of site conditions and cultivars on the contents of antioxidants in potato tubers. Zesz. Probl. Post. Nauk Rol. 511: 245-254.

Hamouz K., Lachman J., Hejtmánkova K., Pazderu K., Čižek M., Dvořák P. 2010. Effect of natural and growing conditions on the content of phenolics in potatoes with different flesh colour. Plant Soil Environ. 56 (8): 368-374.

Jeszka M., Flaczyk E., Kobus-Cisowska J., Dziedzic K. 2010. Związki fenolowe - charakterystyka i znaczenie w technologii żywności. Nauka Przyroda Technologie 4 (2): 1-13. 
Kołodziejczyk M., Ropek D., Szmigiel A. 2010. Kształtowanie się powierzchni asymilacyjnej roślin ziemniaka oraz składu chemicznego bulw w zależności od metody zwalczania stonki ziemniaczanej. Prog. Plant Prot./Post. Ochr. Roślin 50 (1): $477-481$.

Kraska P. 2002. Wpływ sposobów uprawy, poziomów nawożenia i ochrony na wybrane cechy jakości ziemniaka. Zesz. Probl. Post. Nauk Rol. 489: 229-237.

Kuźnicki D. 2006. Antyoksydanty i środki obniżające poziom cholesterolu zawarte w surowcach roślinnych wykazujące działanie przeciwmiażdżycowe. Post. Fitoterapii 4: 206-212.

Leszczyński W. 2000. Jakość ziemniaka konsumpcyjnego. Żywność Nauka Technologia Jakość 4 (25) Supl.: 5-27.

Marwaha R.S. 1988. Nematicides induced changes in the chemical composition constituents of potato tubers. Plant Foods for Human Nutrition 38: 95-103.

Rudzińska B., Mikos-Bielak M. 1998. Modyfikacja chemicznej jakości bulw ziemniaka przez wybrane syntetyczne regulatory wzrostu. Rocz. AR Poznań CCCVII, Roln. 52: 229-234.

Sikora E., Cieślik E., Topolska K. 2008. The sources of natural antioxidants. Acta Sci. Pol., Technol. Aliment. 7 (1): 5-17.

Swain T., Hillis W.E. 1959. The phenolic constituents of Prunus domestica. I. The quantitative analysis of phenolics constituens. J. Sci. Food Agric. 10 (1): 63-68.

Szajdek A., Borowska J. 2004. Właściwości przeciwutleniające żywności pochodzenia roślinnego. Żywność Nauka Technologia Jakość 4 (41): 5-28.

Zarzecka K., Gugała M. 2011. The effect of herbicides and soil tillage systems on the content of polyphenols in potato tubers. Pol. J. Environ. Stud. 20 (2): 513-517.

Ziemlański S., Wartanowicz M. 1999. Rola antyoksydantów żywieniowych w stanie zdrowia i choroby. Pediatria Współczesna 1 (2/3): 97-105. 